\title{
Green manufacturing and environmental productivity growth
}

\begin{abstract}
Purpose Due to stringent regulations on carbon emissions, green manufacturing has become a critical issue in manufacturers' strategic planning. Manufacturers are greening production through carbon abatement activities. This study aims to investigate the factors that influence the effects of carbon abatement on environmental productivity growth.

Design/methodology/approach Using data envelopment analysis with directional distance function, this study examines productivity growth associated with carbon abatement under regulated and unregulated production technologies. A pollution abatement index is constructed for determining the effects of carbon abatement on environmental productivity growth. Panel data of eighteen European countries in paper and pulp and coke sectors are collected for the analysis.

Findings The empirical findings reveal that carbon abatement may positively or negatively affect environmental productivity growth which is dependent on the nature of technology in a sector, the innovation capabilities of a country and environmental regulations.

Originality/value Conventional approaches in measuring productivity changes do not normally take undesired outputs (e.g. carbon emissions) into consideration. This study contributes to literature by constructing a pollution abatement index that considers productivity changes under a joint production technology (where both desired and undesired outputs are considered). The findings enhance current understandings on the effectiveness of carbon abatement activities and help managers establish corporate environmental strategies to adopt green manufacturing.
\end{abstract}

Keywords: Green manufacturing; Environmental productivity; Carbon abatement; Data envelopment analysis

Article Classification: Research paper 


\section{Introduction}

The growing concerns about environmental pollutions and global warming have made governments to develop regulations and policies to reduce greenhouse gas emissions from industrial production (Rao 2004; Vachon and Klassen 2007; Orji and Wei 2016; Kazancoglu et al. 2018). For example, the European Union (EU) committed to the targets of $20 \%$ cut in greenhouse gas emissions (from 1990 levels) and 20\% improvement in energy efficiency (European Commission 2014). The greening of energy intensive sectors, such as iron and steel, paper and pulp, coke and refinery, plays pivotal roles in tackling global climate change because large amounts of greenhouse gas are generated during the production and supply chain processes (World Bank 2007; Rao 2004; Orji and Wei 2016). The $\mathrm{CO}_{2}$ emission reduction has been regarded as the key environmental target under all recent regulatory schemes, including Kyoto protocol (1997), Chicago Climate Exchange (2003), European Union Emissions Trading Scheme (2005), and Climate Change Act (2008).

Stricter regulations on the environment and increasing pressure from public are forcing manufacturers to include environmental factors in their manufacturing strategies and to adopt green manufacturing, which refers to the production systems that minimize the negative impacts of operations on the environment and natural resources (Laosirihongthong et al. 2013; Kazancoglu et al. 2018; Bai et al. 2018). Green manufacturing and carbon abatement may use pollution prevention technologies which rely on improving input quality to reduce emissions of pollutants and the amount of waste (Vachon and Klassen 2007; Chiou et al. 2011) and/or pollution control technologies which focus on capturing, treating or disposing pollutants or harmful by-products in manufacturing processes (Rao 2004; Ouardighi et al. 2016).

To meet regulatory requirements on carbon emission limits, manufacturers are redesigning their production and supply chain operations, and are implementing carbon abatement activities to reduce hazardous emissions, eliminate wasteful resources consumption, mitigate environmental risks and protect natural resources (Toptal et al. 2014; Vachon and Klassen 2007; Ouardighi et al. 2016). However, empirical evidence exists that the implementation of carbon abatement activities may have an adverse effect on an industry's productivity (Ignatius et al. 2016; Pasurka 2008). One possible reason is that traditional productive measures do not consider environmental factors such as undesired outputs (e.g. greenhouse gas) (Zhou et al. 2008). Hence, a joint production technology approach that simultaneously considers both good and bad outputs has been proposed to measure environmental productivity (Quariguasi Frota Neto et al. 2009). However, few studies have estimated productivity growth under regulated and unregulated production technologies for determining the effects of carbon abatement activities on environmental productivity growth. This study aims to investigate the factors that influence the effects of carbon abatement on environmental productivity growth using panel data from paper and pulp and coke industries across eighteen European countries.

Data envelopment analysis (DEA) is a nonparametric method for the estimation of production frontiers (Kahi et al. 2017; Chang et al. 2014). As a mathematical programming based approach, DEA 
has been used for measuring relative efficiency of decision making units (DMUs) that have multiple inputs and outputs (Charnes et al. 1978). This method compares DMUs considering all inputs used and outputs produced, and identifies the most efficient DMUs (Liu et al. 2017). DEA with directional distance function has been widely applied to measure environmental productivity (Chung et al. 1997; Färe et al. 2007; Zhou et al. 2008; Chang et al. 2014; Ouardighi et al. 2016; Liu et al. 2017). For example, Färe et al. (2007) analyse the environmental production performance using the data of 92 coal-fired power plants in the United States. Ramli et al. (2013) investigate the eco-efficiency of the Malaysian manufacturing sectors considering $\mathrm{CO}_{2}$ emissions. Arabi et al. (2017) measure the ecoefficiency of Iranian gas-fired power plants using the data from 2003 to 2010 . We adopt this DEA approach, as we find that the method is particularly relevant since regulators themselves commonly use similar efficiency and productivity measures as management tools and to evaluate policy outcomes. Also the applied DEA method allows us to construct the pollution abatement index (PAI) in the second stage to offer a more explicit implication for the environmental regulatory settings.

We focus on greenhouse gas pollution prevention and control and investigate $\mathrm{CO}_{2}$ emission as the main and common bad output because it has been regarded as the key environmental target under all recent regulatory schemes. We conduct the research in the paper and pulp and coke industries for two reasons. First, both paper and pulp and coke are energy intensive industries which generate considerably high levels of $\mathrm{CO}_{2}$ emissions during the production processes. Carbon abatement activities have significant impacts on environmental productivity growth in the two industries. Second, the two industries have different production processes from inputs to final outputs and rely on different carbon abatement technologies. Comparing the impacts of carbon abatement on environmental productivity growth in the two industries can shed light on the roles played by technologies in green manufacturing. The findings from our empirical analysis provide insights into the impacts of the nature of production technologies and processes of a sector, innovation capabilities of a country and environmental regulations and policies on carbon abatement.

Details of the model and its application are presented in Section 2. Section 3 describes the data and discusses the empirical findings. Section 4 concludes the paper with the key findings and highlights the implications and future research directions.

\section{The model}

In this section, we begin with elaborating the decision-making model using a joint production function through carbon abatement as the reference model. After that, we show the conventional measurement of productivity derived from it. Finally, we construct the PAI using the estimated productivity growth indices to offer a more explicit implication for the environmental regulatory settings.

In consistence with the denotations used in the literature, let $\mathrm{x}=\left(\mathrm{x}_{1}, \ldots, \mathrm{x}_{\mathrm{N}}\right) \in \mathbb{R}_{+}^{\mathrm{N}}$ denotes a vector of inputs, $\mathrm{y}=\left(\mathrm{y}_{1}, \ldots, \mathrm{y}_{\mathrm{M}}\right) \in \mathbb{R}_{+}^{\mathrm{M}}$ denotes a vector of good (desired) outputs, and $\mathrm{b}=$ 
$\left(b_{1}, \ldots, b_{I}\right) \in \mathbb{R}_{+}^{I}$ denotes a vector of bad (undesired) outputs. Thus, the joint production function is specified as:

$\mathrm{P}(\mathrm{x})=\{(\mathrm{y}, \mathrm{b}): \mathrm{x}$ can produce $(\mathrm{y}, \mathrm{b})\}, \mathrm{x} \in \mathbb{R}_{+}^{\mathrm{N}}$,

where the output set $P(x)$ represents the combination of good and bad outputs $(y, b)$ that can be produced using the given input vector $\mathrm{x}$. We consider an output-orientated optimisation problem. $\mathrm{P}(\mathrm{x})$ is a convex and compact set that satisfies the standard properties of no free lunch, possibility of inaction, and strong or free disposability of inputs (Färe et al. 2016).

To assure the joint production of good and bad outputs through carbon abatement activities, it is necessary to impose further two assumptions. They are,

(i) if $(y, b) \in P(x)$ and $b=0$ then $y=0$;

(ii) if $(y, b) \in P(x)$ and $0 \leq \theta \leq 1$ imply $(\theta y, \theta b) \in P(x)$.

The assumption (i) ensures the null-jointness of the output set, meaning that no good outputs can be produced without producing any bad outputs. The second assumption ensures the jointly weak disposability of good and bad outputs, implying that a reduction of the bad outputs is not costless, which may negatively influence the production level of good outputs. It is not unreasonable to argue that carbon abatement activities require resources that otherwise could have been used to increase production of good outputs. Therefore, the joint production technology assumes, in principle, good outputs are economically disposable without cost, nevertheless bad outputs are not, in particular with environmental regulations imposed.

With the above assumptions, the joint production technology can be written into a directional output distance function as defined by Chambers et al. (1998). Thus, we have

$\vec{d}_{o}\left(x, y, b ; g_{y}, g_{b}\right)=\sup \left\{\theta:(y, b)+\left(\theta g_{y}, \theta g_{b}\right) \in P(x)\right\}$

where $g=\left(g_{y}, g_{b}\right)$ and $\theta$ represent the direction and proportion in which the output vector $(y, b)$ is scaled to reach the frontier of the output set $\mathrm{P}(\mathrm{x})$. The directional output distance function value $\theta$ is zero lower-bounded. A value equals to zero indicates the observed output vector is located on the frontier, and thus being technically efficient; otherwise, the output vector is within the frontier, indicating technical inefficiency.

We operationalise the directional output distance model under two situations: (i) when carbon abatement activities are incorporated in the production technology, i.e. $\vec{d}_{o}(x, y, b ; y,-b)$, the directional vector is $g=(y,-b)$; and (ii) when they are not, i.e. $\vec{d}_{o}(x, y, 0 ; y, 0)$, the bad outputs are ignored from the output set $\mathrm{P}(\mathrm{x})$ and the directional vector is $g=(y, 0)$ (Krautzberger and Wetzel 2012). In the first situation (i.e. regulated Model 1) where the producers comply with environmental regulations in which the bad outputs are limited to a certain level, the decision model seeks to increase the good outputs and simultaneously reduce the bad outputs to reach the efficient production frontier along the direction $g=(y,-b)$. For given inputs, in an output-orientated approach, some inputs are reallocated as abatement costs in the production process. That implies that certain level of good 
outputs production is likely to be sacrificed to meet the regulated limit of the bad outputs. In the second situation (i.e. unregulated Model 2), there is no environmental regulation imposed. We assume that all inputs are used to produce good outputs; the bad outputs are ignored from the output set. The unregulated Model 2 is thus the conventional optimisation approach that seeks to solely expand the good outputs for given inputs (i.e., to expand the original output vector $(y, 0)$ along the direction $g=$ $(y, 0)$ to the efficient frontier). Figure 1 illustrates the two directional output distance models.

\section{Insert Figure 1 about here}

In this application, we calculate the Sequential Malmquist productivity change index (SM) introduced by $\mathrm{Oh}$ and Heshmati (2010). The $S M$ measure is different from the conventional Malmquist index in the way how the frontier is defined. The sequential efficient frontier of each year is defined relative to all observations from the preceding years in the sample. In other words, each year's frontier is measured by taking all past information including all preceding technologies into account. The output set is thus specified as:

$\bar{P}^{t}\left(x^{t}\right)=P^{1}\left(x^{1}\right) \cup P^{2}\left(x^{2}\right) \cup \ldots \cup P^{t}\left(x^{t}\right), \quad t=1, \ldots, T$

Therefore, by definition the $S M$ index eliminates every possibility of technological regression in the production over the observation years. Following Oh and Heshmati (2010), the SM index between periods $t$ and $t+1$ is given by:

$S M_{t}^{t+1}=\left[\frac{\left[1+\vec{d}_{o}^{t}(t)\right]}{\left[1+\vec{d}_{o}^{t}(t+1)\right]} \times \frac{\left[1+\vec{d}_{o}^{t+1}(t)\right]}{\left[1+\vec{d}_{o}^{t+1}(t+1)\right]}\right]^{\frac{1}{2}}$

Similar to the conventional Malmquist index, the $S M$ index is a geometric mean of two productivity indices. The first part is measured by the ratio of the two output distances in periods $t$ and $t+1$ with respect to the period $t$ technology and the second with respect to the period $t+1$ technology. To calculate the $S M$ index, four directional distance functions must be defined and solved. The notation $\vec{d}_{o}^{t}(t)$ represents the directional output distance function, $\vec{d}_{o}^{t}\left(x^{t}, y^{t}, b^{t} ; g_{y}^{t}, g_{b}^{t}\right)$, measuring the distance of production in the period $t$ relative to the period $t$ technology. And the notation $\vec{d}_{o}^{t+1}(t)$ represents the directional output distance function, $\vec{d}_{o}^{t+1}\left(x^{t}, y^{t}, b^{t} ; g_{y}^{t}, g_{b}^{t}\right)$, which measures the distance of production in the period $t$ relative to the period $t+1$ technology.

The $S M$ index can be decomposed into two components: efficiency change $\left(E_{t}^{t+1}\right)$ and technological change $\left(T_{t}^{t+1}\right)$, indicating underlying factors contributing to the productivity change. It is written as,

$S M_{t}^{t+1}=E_{t}^{t+1} \times T_{t}^{t+1}$

where,

$E_{t}^{t+1}=\frac{\left[1+\vec{d}_{o}^{t}(t)\right]}{\left[1+\vec{d}_{o}^{t+1}(t+1)\right]}$

and 
$T_{t}^{t+1}=\left[\frac{\left[1+\vec{d}_{o}^{t+1}(t)\right]}{\left[1+\vec{d}_{o}^{t}(t)\right]} \times \frac{\left[1+\vec{d}_{o}^{t+1}(t+1)\right]}{\left[1+\vec{d}_{o}^{t}(t+1)\right]}\right]^{\frac{1}{2}}$

$E_{t}^{t+1}$ measures the change in output efficiency between two periods, which is the ratio of the distances of observations to their respective regulated frontiers, measured in terms of proportionally expanded good outputs and contracted bad outputs. A shift of the production frontier between two adjacent periods $t$ and $t+1$ is measured by $T_{t}^{t+1}$. Table 1 summarises the technical implications of these three indices.

\section{Insert Table 1 about here}

To operationalise Equation (4), we follow Färe et al. (2001)'s non-parametric DEA approach. We start with the regulated Model 1 . Let $\tau=1, \ldots, T$ time periods and $k=1, \ldots, K$ observations of inputs and outputs $\left(x^{k, \tau}, y^{k, \tau}, b^{k, \tau}\right)$, we specify the sequential directional output distance function for each observation $k^{\prime}$ at the time $t$ as the following linear program (LP):

$$
\begin{array}{ll} 
& \vec{d}_{o}^{t}\left(x^{t, k^{\prime}}, y^{t, k^{\prime}}, b^{t, k^{\prime}} ; g_{y}^{t, k^{\prime}}, g_{b}^{t, k^{\prime}}\right)=\max \theta \\
\text { s.t. } & \sum_{\tau=1}^{t} \sum_{k=1}^{K} z_{k}^{\tau} y_{k m}^{\tau} \geq(1+\theta) y_{k^{\prime} m}^{t}, m=1, \ldots, M \\
& \sum_{\tau=1}^{t} \sum_{k=1}^{K} z_{k}^{\tau} b_{k i}^{\tau}=(1-\theta) b_{k^{\prime} i}^{t}, i=1, \ldots, I \\
& \sum_{\tau=1}^{t} \sum_{k=1}^{K} z_{k}^{\tau} x_{k n}^{\tau} \leq x_{k^{\prime} n}^{t}, n=1, \ldots, N \\
& z_{k}^{\tau} \geq 0, k=1, \ldots, K
\end{array}
$$

where $z_{k}^{\tau}$ is a vector of optimal weights defined by optimization LP problem to construct the efficient frontier. The imposed non-negative constraint (iv) on the $z_{k}^{\tau}$ indicates that constant returns to scale in the production technology are assumed (Chung et al. 1997). Constraints (i) and (iii) ensure that the productive efficiency of observation $k^{\prime}$ is maximized subject to the restriction that the efficiencies of all observations must be less than or equal to one. The strict equality constraint (ii) together with constraint (i) allow for the jointly weak disposability of the good and bad outputs. Solving the above LP using the same inputs, the value of $\theta$ measures the extent to which the good and bad outputs can conceivably and proportionally be increased and decreased relative to all other observations in the sample. The null-jointness assumption is guaranteed by the following two constraints on the bad outputs:

$\sum_{k=1}^{K} b_{k i}^{\tau}>0, \quad i=1, \ldots, I$ and $\tau=1, \ldots T$

$\sum_{i=1}^{I} b_{k i}^{\tau}>0, \quad k=1, \ldots, K$ and $\tau=1, \ldots T$

that is, at least one bad output is produced by at least one observation $k$ at each time $\tau$. This can be seen from taking $b_{k^{\prime} i}^{t}=0$, for $i=1, \ldots, I$ in (8) so that $z_{k}^{\tau}=0, k=1, \ldots, K$, and so does $y_{k^{\prime} m}^{t}=$ $0, m=1, \ldots, M$ (i.e. no output is produced) (Färe et al. 2016).

The LPs for $\vec{d}_{o}^{t}(t+1), \vec{d}_{o}^{t+1}(t)$ and $\vec{d}_{o}^{t+1}(t+1)$ can be specified analogically. The four LPs altogether represent the regulated Model 1, i.e. the joint production technology through environmental 
regulations. Solving regulated Model 1, we obtain the environmental productivity change index $\left(S M_{g b}\right)$.

To estimate PAI, which is defined as a ratio of productivity changes from unregulated and regulated models for implication of abatement costs, we next specify the unregulated Model 2, i.e. ignoring bad outputs from the production process (Aiken et al. 2009). We drop the equality constraint (ii) in (8) and the constraints (9) and (10). Thus, the value of $\theta$ in the unregulated Model 2 measures, for given inputs, the extent to which the good outputs can be expanded relative to the efficient frontier while ignoring bad outputs. The directional distance function for the unregulated Model 2 is $\vec{d}_{o}^{t}\left(x^{t, k^{\prime}}, y^{t, k^{\prime}}, 0 ; y^{t, k^{\prime}}, 0\right)=\max \theta$ in which the bad outputs are excluded. That means the LPs is to optimize solely the good outputs, for given inputs. Solving the unregulated Model 2, we obtain the other set of productivity change index $\left(S M_{g}\right)$.

We use the two sets of productivity change indices obtained from our afore-defined unregulated and regulated models to estimate the PAI as:

$\mathrm{PAI}=\frac{S M_{g}}{S M_{g b}}$

Table 2 summarises the technical meanings and implications of the PAI.

\section{Insert Table 2 about here}

\section{Analysis and results}

\subsection{Data}

The industry level production data for the paper and pulp and coke sectors in EU countries were collected from the OECD Structural Analysis (STAN) Database (https://unstats.un.org/unsd/cr/registry/regcst.asp? $\mathrm{Cl}=2 \& \mathrm{Top}=2 \& \mathrm{Lg}=1$ ). Given some underlying data problems on missing value and consistency, we finally compiled a balanced panel dataset containing aggregated information on industrial input and output variables for eighteen EU countries over the period 1995-2006 for empirical analysis. Table 3 lists the sample countries.

\section{Insert Table 3 about here}

Gross output was used as the good (desired) output, whereas $\mathrm{CO}_{2}$ emissions were used as the bad (undesired) output. The input and output data were measured in local currency units at current prices, except that employees were measured in numbers. GDP deflators from the OECD were used to transform those series into constant prices based on the year 2000. For cross-country comparisons, the local currency measures were converted into an international common unit using purchasing power parities collected from the OECD (OECD 2001). For each sector studied, the input variables were intermediate inputs (incl. energy, materials and services), capital stock and number of employees. We applied the standard perpetual inventory method to calculate the capital stock for our analyses (Aiken et al. 2009; Krautzberger and Wetzel 2012). In our specified formula, $K_{s, i, t}=$ 
$(1-\delta) K_{s, i, t-1}+I_{s, i, t}$, we assumed a $5 \%$ country average depreciation rate (denoted by $\delta$ ) for both paper and pulp and coke sectors. $K_{s, i, t}$ and $I_{s, i, t}$ are the capital stock and the gross fixed capital formation (GFCF) for sector $s$ in country $i$ at time $t$. The initial capital stock for each sector in each country can be calculated by $I_{0} /\left(g_{I}+\delta\right)$, the ratio of the 1994 GFCF to the sum of the country average growth rate of GFCF and average depreciation rate.

The data on $\mathrm{CO}_{2}$ emissions were extracted from Eurostat's Air Emissions Accounts (AEA) (http://ec.europa.eu/eurostat/web/environment/emissions-of-greenhouse-gases-and-air-pollutants/airemissions-accounts) which reports air emissions by the economic activities from which the emissions are originated. The production and consumption activities were classified according to the Statistical Classification of Economic Activities in the European Community. This classification is compatible with the ISIC (United Nations International Standard Industrial Classification) used in the STAN Database and hence allows us to combine $\mathrm{CO}_{2}$ emissions from economic activities with economic figures on the industry level. Table 4 presents the statistical summary of inputs and outputs by sector.

\section{Insert Table 4 about here}

We presented three important production and environmental indicators for both sectors across countries over the twelve years (1995-2006) in Table 5, where the major national producers and the top $\mathrm{CO}_{2}$ emitters were identified. The first three columns presented, in sequence, cross-country information on the gross output (i.e. good output), $\mathrm{CO}_{2}$ emissions (i.e. bad output) and $\mathrm{CO}_{2}$ intensity calculated as the ratio of $\mathrm{CO}_{2}$ emissions to gross output production for the paper and pulp sector. The later three columns reported the information for coke sector in the same order. In line with jointly weak disposability of good and bad outputs in the production, the two sectors shared a common pattern in which a country's high-level $\mathrm{CO}_{2}$ emissions was generally associated with a high level gross production in that country, but not necessarily to be low with a low level gross production. This could be observed, for example, the top seven paper and pulp producers (i.e. DE, IT, FR, UK, FI, ES and SE whose twelve-year's average gross productions were arranging from 30,400 to 11,200 million US\$s, above cross-country average at 9,330 million US\$s) were all associated with high levels of $\mathrm{CO}_{2}$ emissions ranging from 6,549 to 2,270 thousand tons (i.e. above the average level at 2,202 thousand tons across country). However, among those, for example, a lower level of gross output $(19,200$ million US\$s) in FR was accompanied with a relatively higher level of $\mathrm{CO}_{2}$ emissions $(5,623$ thousand tons) compared to those in IT (an average gross output at 21,000 million US\$s is associated with 4,981 thousand tons $\mathrm{CO}_{2}$ emission on average). Furthermore, the value of $\mathrm{CO}_{2}$ intensity revealed the insight that the smallest paper and pulp producer, SL, had the highest $\mathrm{CO}_{2}$ intensity with 0.58 . In contrast, five out of the seven top producers were all featured by an intensity level below across country average of 0.25 .

\section{Insert Table 5 about here}


There were some distinctions in the coke sector, while the common pattern held. Unlike the paper and pulp sector, six out of seven top coke producers (i.e. DE, IT, ES, UK, NL and PL) were featured with above average $\mathrm{CO}_{2}$ intensities ranging from 0.62 to 0.96 . The exception country was $\mathrm{BE}$ demonstrating super eco-production with a very low $\mathrm{CO}_{2}$ intensity level of 0.1 . Furthermore, it could be seen from the mean values that the $\mathrm{CO}_{2}$ intensity of coke sector was more than doubled the value of paper and pulp sector. This implied that the pollution level in coke production was generally higher, which was determined by the nature of technology of the two sectors. The environmental impacts of the production of pulp and paper mainly result from the pulping and bleaching processes (Ackermann et al. 1999). The coke oven is a major source of fugitive air emissions and coal charging, coke pushing and quenching are major sources of dust emissions. Coke production generally has a higher emission generation rate in terms of kilograms per metric ton $(\mathrm{kg} / \mathrm{t})$ compared to pulp and paper production (Ackermann et al. 1999).

\subsection{Findings and discussion}

In this section, we present our estimation results on productivity change indices obtained from the unregulated and regulated models. We discuss the impact of carbon abatement activities on productivity change using the insights from PAI. Table 6 presents the average productivity changes under the unregulated and regulated production technologies over the period of 1995-2006 by sector.

\section{Insert Table 6 about here}

\subsubsection{Impact of the nature of technology in a sector}

It can be seen from the value of PAI (0.996) in Table 6, introducing carbon abatement in the paper and pulp sector, in general, has an improving effect on its productivity, despite the decreases in both productivity measures. Such improving effect is driven by a greater environmental technological progress with $3.85 \%$ over $1995-2006$, compared to $2.42 \%$ progress in conventional production technology over the same period. In contrast, the PAI value (1.004) for the coke sector suggests that the introduction of carbon abatement slows down the overall productivity growth. This can be decomposed into the slowdown in both efficiency growth and technological progress in the coke production. Despite the common trend in the technological progress across all countries in EU, the decrease in environmental efficiencies of many countries' coke production suggests that the coke production, on average, is moving away from the efficient production frontier since the carbon abatement activities are imposed.

The result indicates the coke sector is more sensitive to the opportunity cost of the carbon abatement activities compared to paper and pulp sector. The two sectors focus on different practices and technologies for pollution prevention and control. Although the design of the facility layout and the use of water spray systems can manage emissions in coke production, improving the quality of coal feed to coke production is more important for preventing pollution. The use of high-grade coal can reduce cooking time, increase throughput, reduce fuel consumption, and minimize thermal shock to refractory bricks (Ackermann et al. 1999). Hence, the carbon abatement must focus on both 
transformed (e.g. raw materials) and transforming (e.g. facilities and equipment) resources of the production processes and coke manufacturers mainly rely on pollution prevention technologies. In the paper and pulp production, process modifications and advanced equipment are essential for reducing the generation of air emissions (Ackermann et al.1999). Hence, the carbon abatement mainly focuses on the transforming resources and paper and pulp manufacturers rely on pollution control technologies. Introducing carbon abatement in the coke sector requires manufacturers to use better raw materials in operations, which may reduce the input levels and the total productivity. Therefore, a comparison between the coke and paper and pulp sectors reveals that the relationship between carbon abatement and productivity is influenced by the nature of the technologies and their impacts on the transformed and transforming resources of the production processes.

\subsubsection{Impact of the innovation capability of a country}

Figures 2 and 3 illustrate the patterns of $\mathrm{SM}_{\mathrm{g}}, \mathrm{SM}_{\mathrm{gb}}$ and PAI for the sample countries in the two sectors respectively. The cross-country comparisons reveal that two (i.e. ES and FI) main paper and pulp and three (i.e. ES, NL and UK) main coke producers have been slightly worse off in terms of their productivity growth over 1995-2006 (Table 7). According to the Global Innovation Index 20082009 (INSEAD 2009), the majority of the main European paper and pulp and coke producers have high innovation capabilities. They have developed industrial innovations to prevent and control pollutions. For example, the paper and pulp producers have developed innovative equipment for dry debarking, low-odour design black liquor recovery furnace, and advanced steam boilers, heating systems and vacuum pumps. Coke producers have developed loading and unloading equipment to minimize the height of coal drop to the stockpile, water spray systems and/or polymer coatings to reduce the formation of fugitive dust from coal storage and enclosed conveyors combined with extraction and filtration equipment on conveyor transfer. DE, UK, DK and NL were among the top ten counties in terms of innovation outputs (INSEAD 2009). In the paper and pulp sector, transforming resources of the operations play critical roles in pollution control. Hence, the main European paper and pulp producers who have high innovation capabilities can develop advanced technologies that can control pollution and improve productivity at the same time. However, in the coke sector, both transformed and transforming resources of the operations must be improved for preventing pollution. Developing and adopting advanced abatement technologies alone cannot guarantee the productivity increases. Although NL and UK have high innovation capabilities to develop advanced abatement technologies, they may fail to improve the transformed resources. Therefore, the adoption of carbon abatement reduces productivity. In addition, ES was ranked at the $31^{\text {st }}$ position in terms of innovation outputs, the lowest among all major paper and pulp and coke producers (INSEAD 2009). ES lacks the innovation capabilities to develop advanced abatement technologies and hence we find that introducing carbon abatement reduces productivity in both sectors.

Insert Table 7, Figure 2 and Figure 3 about here 


\subsubsection{Impact of environmental regulations}

The Kyoto Protocol, which was adopted in 1997, is an international treaty which extends the 1992 United Nations Framework Convention on Climate Change and commits State Parties to reduce greenhouse gas emissions. The main goal of the Kyoto Protocol is to control emissions of the main human-emitted greenhouse gases. The European countries have an obligation to reduce emissions and must meet their emission limitation commitments according to the Kyoto Protocol. The European Union Emissions Trading System (EU ETS), which was launched in 2005, aims to fight global warming using the "cap and trade" principle. A maximum (cap) is set on the total amount of greenhouse gases that can be emitted by all participating installations. If emission exceeds what is permitted by its allowances, an installation must purchase allowances from others. Conversely, if an installation has performed well at reducing its emissions, it can sell its leftover credits. We have calculated the productivity changes after the implementation of the Kyoto Protocol and EU ETS respectively (Table 8). In general, across our sample countries, the performance of the coke sector is more sensitive to the environmental regulations than the paper and pulp sector. This can be seen from more significant technology progresses in the coke sector immediately after the two events in 1998 and 2006 with an average increase of $0.46 \%$ and $1.30 \%$, respectively (Table 8). We also find that the Kyoto Protocol and EU ETS have different impacts on carbon abatement and environmental productivity. After the adoption of Kyoto Protocol, there is an increase on the productivity of introducing carbon abatement whereas the launch of the EU ETS reduces the productivity of carbon abatement in both sectors. This finding can be explained by the objectives and mechanisms of the two environmental regulations. The Kyoto Protocol mainly sets targets for greenhouse gas emissions and hence coke and paper and pulp manufacturers are motivated to invest in developing and adopting advanced carbon abatement technologies that can improve productivity. The EU ETS allows manufacturers to sell emission allowance. Some manufacturers may find it is more profitable for them to operate below their full capacities and sell the allowances to others. Hence, instead of investing to improve carbon abatement technologies, the manufacturers may prefer to reduce the production to control the emissions.

\section{Insert Table 8 about here}

\section{Conclusions}

This study constructs a PAI using a joint production approach. Using data collected from paper and pulp and coke sectors in European countries over the period of 1995-2006, this study provides empirical evidence that carbon abatement may either improve or reduce environmental productivity growth. By comparing the productivity changes in the two sectors, the findings reveal that the carbon abatement activities that focus on the transformed resources of operations may reduce environmental productivity whereas those focus on the transforming resources of operations may improve environmental productivity. We also conduct across country comparisons and the results indicate that 
introducing carbon abatement in countries with high innovation capabilities tend to improve environmental productivity. Finally, we investigate the effects of two kinds of environmental regulations by comparing the productivity changes and find that the Kyoto Protocol positively whereas the EU ETS negatively affects the impacts of carbon abatement on environmental productivity.

The results have three main implications for practitioners and policy makers. First, the findings indicate that an abatement activity reduces productivity if it focuses on transformed resources whereas an abatement activity improves productivity if it improves transforming resources. Therefore, we suggest practitioners analyse the nature of the technologies and production processes when adopting carbon abatement activities. We suggest managers in energy intensive industries identify and focus on the transforming resources of the production processes to improve productivity in the greening of manufacturing. Advanced machines and equipment should be developed and adopted in the production processes to green supply chains and reduce carbon emissions. When designing products and processes, managers should consider the carbon emissions of the products' entire life-cycle. Trainings and incentives should be provided to managers and employees to motivate and facilitate them to learn and implement green manufacturing processes and technologies. Second, the findings reveal that the innovation capabilities of a country have significant impacts on the environmental productivity growth. Manufacturers in the countries with high research and development capabilities can reduce carbon emissions and improve environmental productivity at the same time. Therefore, we suggest policy makers devise policies and regulations to promote manufacturers to invest in research and development on carbon abatement technologies. Government officials should also provide grants for universities and research institutes to support low carbon manufacturing research. Government officials should organise events and design policies to promote university and industry collaboration, the knowledge transfer between researchers and practitioners, and the commercialization of the research outputs on green manufacturing and carbon abatement. Third, we find that the objectives and mechanisms of environmental regulations affect the environmental productivity growth. Policy makers should be aware that a regulation directly controlling the amount of carbon emissions may lead to environmental productivity growth because manufacturers will invest in and adopt green manufacturing technologies and practices whereas a regulation indirectly controlling carbon emissions through trading market may drive some manufacturers to decrease production and sell their quotas in the market which allow resources to flow to the efficient manufacturers in the industry. Therefore, policy makers should devise the environmental regulations according to the objectives of controlling the overall carbon emissions and/or optimising the resources allocation in an industry.

The conclusions are based on the empirical data collected from two sectors in European countries from 1995 to 2006, which is a limitation of this study. Data over a longer term could provide more insights into the influences of the environmental regulations and major industrial innovations. Future studies could also apply the approach to other sectors with different technological characteristics and 
other countries with different innovation capabilities to validate and generalise the findings related to the impacts of industry and country characteristics on the effects of carbon abatement on environmental productivity growth. In addition, this study mainly focuses on greenhouse gas emissions. Other air and water pollutions also have significant and negative environmental impacts. Future studies can investigate the overall impacts of air and water pollutants reduction on resource efficiency and circular economy.

\section{References}

Abadir, K. and Talmain, G. (2001), "Depreciation rates and capital stocks." The Manchester School, Vol. 69, No.1, pp.42-51.

Ackermann, R.O., Aggarwal, S. Dixon, J.R., Fitzgerald, A.D., Hanrahan, D. C., Hughes, G.A. Kunte, A., Lovei, M., Lvovsky, K., and Somani, A. H. (1999), "Pollution prevention and abatement handbook, 1998: Toward cleaner production". Washington: The World Bank Group, Available at: http://documents.worldbank.org/curated/en/758631468314701365/Pollutionprevention-and-abatement-handbook-1998-toward-cleaner-production.

Aiken, D. V., Färe, R., Grosskopf, S. and Pasurka, C.A. (2009), "Pollution abatement and productivity growth: Evidence from Germany, Japan, the Netherlands, and the United States". Environmental and Resource Economics, Vol.44, No.1, pp.11-28.

Arabi, B., Doraisamy, S,M., Emrouznejad, A, and Khoshroo, A. (2017), "Eco-efficiency measurement and material balance principle: An application in power plants Malmquist Luenberger Index." Annals of Operations Research, Vol.255, No.1/2, pp. 221-39.

Bai, C., Shah, P., Zhu, Q., and Sarkis, J. (2018), “Green product deletion decisions: An integrated sustainable production and consumption approach". Industrial Management and Data Systems, Vol.118, No.2, pp.349-89.

Chambers, R. G., Chung, Y., and Färe, R. (1998), "Profit, directional distance functions, and Nerlovian efficiency". Journal of Optimization Theory and Applications, Vol.98, No.2, pp.351-64.

Charnes A, Cooper, WW, and Rhodes E. (1978), "Measuring the efficiency of decision making units". European Journal of Operational Research, Vol.2, No.6, pp. 429-44.

Chang, Y.T., Park, H., Jeong, J. and Lee, J. (2014), "Evaluating economic and environmental efficiency of global airlines: A SBM-DEA approach." Transportation Research Part D: Transport and Environment, Vol. 27, No. March 2014, pp. 46-50.

Chiou, T., Chan H.K., Lettice, F. and Chung, S.H. (2011), "The influence of greening the suppliers and green innovation on environmental performance and competitive advantage in Taiwan." Transportation Research Part E: Logistics and Transportation Review, Vol.47, No.6, pp.822-36. 
Chung, Y.H., Färe, R. and Grosskoft. S, (1997), "Productivity and undesirable outputs: A directional distance function approach." Journal of Environmental Management, Vol.51, No.3, pp.22940.

European Commission. (2014), "Communication taking stock of the Europe 2020 strategy." Available at: http://ec.europa.eu/europe2020/pdf/europe2020stocktaking_en.pdf.

Färe, R., Grosskopf, S., and Pasurka Jr., C.A. (2001), "Accounting for air pollution emissions in measures of state manufacturing productivity growth". Journal of Regional Science, Vol.41, No.3, pp.381-409.

Färe, R., Grosskoft, S., and Pasurka Jr., C.A. (2007), "Environmental production functions and environmental directional distance functions." Energy, Vol.32, No.7, pp.1055-66.

Färe, R., Grosskopf, S., and Pasurka Jr., C.A. (2016), "Technical change and pollution abatement costs." European Journal of Operational Research, Vol.248, No.2, pp.715-24.

INSEAD. (2009), "Global innovation index 2008-2009". Available at: https://www.globalinnovationindex.org/userfiles/file/gii-2008-2009-report.pdf.

Ignatius, J., Ghasemi, M.R., Zhang, F., Emrouznejad, A., and Hatami-Marbini, A. (2016) "Carbon efficiency evaluation: An analytical framework using fuzzy DEA." European Journal of Operational Research, Vol.253, No.2, pp.982-96.

Kahi, V.S., Yousefi, S., Shabanpour, H., and Saen, R.F., (2017), "How to evaluate sustainability of supply chains? A dynamic network DEA approach". Industrial Management and Data Systems, Vol.117, No.9, pp.1866-89.

Kazancoglu, Y., Kazancoglu, I., and Sagnak, M., (2018), "Fuzzy MEDMATEL-based green supply chain management performance: An application in cement industry". Industrial Management and Data Systems, Vol. 118, No.2, pp.412-31.

Krautzberger, L. and Wetzel, H. (2012), "Transport and $\mathrm{CO}_{2}$ : Productivity growth and carbon Dioxide emissions in the European commercial transport industry". Environmental and Resource Economics, Vol.53, No.3, pp.435-54.

Laosirihongthong, T., Adebanjo, D., and Tan, K.C., (2013), "Green supply chain management practices and performance." Industrial Management and Data Systems, Vol.113, No.8. pp.1188-09.

Liu, H., Zhang, Y., Zhu, Q. and Chu, J. (2017), "Environmental efficiency of land transportation in China: A parallel slack-based measure for regional and temporal analysis." Journal of Cleaner Production, Vol. 142, No. 2, pp. 867-76.

OECD. (2001), "Measuring productivity - OECD manual: Measurement of aggregate and industrylevel productivity growth." Available at: http://www.oecd-ilibrary.org/industry-andservices/measuring-productivity-oecd-manual_9789264194519-en. 
Oh, D. and Heshmati, A. (2010), "A sequential Malmquist-Luenberger productivity index: Environmentally sensitive productivity growth considering the progressive nature of technology". Energy Economics, Vol. 32, No.6, pp.1345-55.

Orji, I. and Wei, S. (2016), "A detailed calculation model for costing of green manufacturing". Industrial Management and Data Systems, Vol.116, No.1, pp.65-86.

Ouardighi, F.E., Sim, J.E., and Kim, B. (2016), "Technical change and pollution abatement costs." European Journal of Operational Research, Vol.248, No.2, pp.715-24.

Pasurka, C. (2008), "Perspective on pollution abatement and competitiveness: Theory, data, and analyses." Review of Environmental Economics and Policy, Vol.2, No.2, pp.194-218.

Quariguasi Frota Neto, J., Walther, G., Bloemhof, J., van Nunen, J.A.E.E., and Spengler, T. (2009), "A methodology for assessing eco-efficiency in logistics networks." European Journal of Operational Research, Vol.193, No.3, pp.670-82.

Ramli, N.A., Munisamy, S., and Arabi, B. (2013), "Scale directional distance function and its application to the measurement of eco-efficiency in the manufacturing sector." Annals of Operations Research, Vol. 211, No.1, pp.381-98.

Rao, P. (2004), "Greening production: A south-east Asian experience." International Journal of Operations \& Production Management, Vol.24, No.3, pp.289-320.

Toptal, A., Ozlu, H., and Konur, D. (2014), "Joint decisions on inventory replenishment and emission reduction investment under different emission regulations." International Journal of Production Research, Vol.52, No.1, pp.243-69.

Vachon, S., and Klassen, R.D, (2007), "Supply chain management and environmental technologies: The role of integration." International Journal of Production Research, Vol.45, No.2, pp.40123.

World Bank. 2007. "Environmental, health, and safety guidelines." The World Bank Group. Available at: http://www.ifc.org/wps/wcm/connect/554e8d80488658e4b76af76a6515bb18/Final\%2B\%2BGeneral\%2BEHS\%2BGuidelines.pdf?MOD=AJPERES.

Zhou, P., Ang, B.W., and Poh. K.L. (2008), "A survey of data envelopment analysis in energy and environmental studies." European Journal of Operational Research, Vol.189, No.1, pp.1-18. 